\title{
Cannabinoid Agonists but not Inhibitors of Endogenous Cannabinoid Transport or Metabolism Enhance the Reinforcing Efficacy of Heroin in Rats
}

\author{
Marcello Solinas',2, Leigh V Panlilio', Gianluigi Tanda ${ }^{3}$, Alexandros Makriyannis', Stephanie A Matthews' \\ and Steven R Goldberg*, I \\ 'Preclinical Pharmacology Section, Behavioral Neuroscience Branch, Intramural Research Program, National Institute on Drug Abuse, National \\ Institutes of Health, Department of Health and Human Services, Baltimore, MD, USA; ${ }^{2}$ Laboratoire de Biologie et Physiologie Cellulaires, \\ CNRS-6 187, University of Poitiers, Poitiers, France; ${ }^{3}$ Psychobiology Section, Medications Discovery Research Branch, Intramural \\ Research Program, National Institute on Drug Abuse, National Institutes of Health, Department of Health and Human Services, \\ Baltimore, MD, USA; ${ }^{4}$ Center for Drug Discovery, Northeastern University, Boston, MA, USA
}

\begin{abstract}
Accumulating evidence suggests that the endogenous cannabinoid system is involved in the reinforcing effects of heroin. In rats intravenously self-administering heroin, we investigated effects of cannabinoid $C B_{1}$ receptor agonists and compounds that block transport or metabolism of the endogenous cannabinoid anandamide. The natural cannnabinoid $\mathrm{CB}_{1}$ receptor agonist delta-9-tetrahydrocannabinol (THC, $0.3-3 \mathrm{mg} / \mathrm{kg}$ i.p.) did not alter self-administration of heroin under a fixed-ratio one (FRI) schedule, except at a high $3 \mathrm{mg} / \mathrm{kg}$ dose which decreased heroin self-administration. Under a progressive-ratio schedule, however, THC dose-dependently increased the number of $50 \mu \mathrm{g} / \mathrm{kg}$ heroin injections self-administered per session and the maximal ratio completed (break-point), with peak increases at I mg/kg THC. In addition, I mg/kg THC increased break-points and injections self-administered over a wide range of heroin injection doses $(25-100 \mu \mathrm{g} / \mathrm{kg})$, indicating an increase in heroin's reinforcing efficacy and not its potency. The synthetic cannabinoid CB, receptor agonist WIN55,2I2-2 (0.3-3 mg/kg i.p.) had effects similar to THC under the progressive-ratio schedule. In contrast, AM-404 (I - I 0 mg/ kg i.p.), an inhibitor of transport of anandamide, and URB-597 (0.0I-0.3 mg/kg i.p.), an inhibitor of the enzyme fatty acid amide hydrolase $(F A A H)$ that degrades anandamide, or their combination, did not increase reinforcing efficacy of heroin at any dose tested. Thus, activation of cannabinoid $C B_{1}$ receptors facilitates the reinforcing efficacy of heroin and this appears to be mediated by interactions between cannabinoid $\mathrm{CB}_{\text {I }}$ receptors and mu-opioid receptors and their signaling pathways, rather than by an opioid-induced release of endogenous cannabinoids.

Neuropsychopharmacology (2005) 30, 2046-2057. doi:I 0. I038/sj.npp. I 300754; published online 4 May 2005
\end{abstract}

Keywords: heroin; THC; drug self-administration; progressive-ratio schedule; endocannabinoids; reinforcement

\section{INTRODUCTION}

It has been repeatedly demonstrated that treatment with the cannabinoid $\mathrm{CB}_{1}$ receptor antagonist Rimonabant (SR$141716 \mathrm{~A})$ can decrease the reinforcing effects of heroin (Navarro et al, 2001; Caille and Parsons, 2003; De Vries et al, 2003; Solinas et al, 2003). In addition, mice lacking cannabinoid $\mathrm{CB}_{1}$ receptors are less sensitive to the

\footnotetext{
*Correspondence: Dr SR Goldberg, Preclinical Pharmacology Section, Behavioral Neuroscience Research Branch, National Institute on Drug Abuse, Division of Intramural Research, National Institutes of Health, 5500 Nathan Shock Drive, Baltimore, MD 21224, USA, Tel: + 410550 I522, Fax: + 410550 1648, E-mail sgoldber@intra.nida.nih.gov Received I4 February 2005; revised 17 March 2005; accepted 21 March 2005

Online publication: 3I March 2005 at http://www.acnp.org/citations/ NPP03310505094/default.pdf
}

reinforcing effects of morphine (Ledent et al, 1999; Martin et al, 2000; Cossu et al, 2001), and in these mice morphine does not increase dopamine levels in the nucleus accumbens (Mascia et al, 1999). These findings strongly support the hypothesis that the endogenous cannabinoid system plays an important role in the reinforcing effects of opioids.

A possible mechanism underlying these effects is that activation of opioid receptors by heroin or morphine results in the release of endogenous cannabinoids and, consequently, in the activation of cannabinoid $\mathrm{CB}_{1}$ receptors. A similar mechanism has been proposed for the reduction of the reinforcing effects of delta-9-tetrahydrocannabinol (THC), the major psychoactive ingredient in marijuana, by opioid antagonists (Tanda and Goldberg, 2003; Justinova et al, 2004; Solinas and Goldberg, 2004; Solinas et al, 2004b). Systemic administration of THC, in fact, increases extracellular levels of the endogenous opioid receptor ligand 
beta-endorphin in both the ventral tegmental area (VTA) and the nucleus accumbens, and injection of beta-endorphin into the VTA markedly enhances the ability of rats to discriminate the effects of experimenter-administered THC (Solinas et al, 2004b). In addition, it has been shown that cannabinoid $\mathrm{CB}_{1}$ receptors and mu- and delta-opioid receptors in the striatum are strongly linked at the intracellular level (Berrendero et al, 2003). Thus, on one hand, cannabinoid receptor agonists can release endogenous opioids, and, on the other hand, stimulation of opioid receptors can facilitate the signal transduction of cannabinoid receptors. Therefore, it is likely that opioid agonists facilitate certain effects of THC by mimicking some of the effects of endogenous opioids released by THC and, at the same time, facilitating cannabinoid $\mathrm{CB}_{1}$ receptor-induced effects at the intracellular level. Conversely, the reduction of THC's effects by opioid antagonists is likely due to blockade of the effects of endogenous opioids released by THC and antagonism of $\mathrm{CB} 1$ receptor-induced effects at the intracellular level.

Of the known endogenous ligands for cannabinoid $\mathrm{CB}_{1}$ receptors, anandamide is one of the best characterized (Freund et al, 2003; Piomelli, 2003; Di Marzo et al, 2004). It is synthesized on demand, binds with a high affinity to cannabinoid $\mathrm{CB}_{1}$ receptors and is rapidly inactivated by a twostep mechanism consisting of uptake into cells by a membrane transporter (Di Marzo et al, 1994; Beltramo et al, 1997; Fegley et al, 2004, 2005; Ortega-Gutierrez et al, 2004) where it is then degraded by the enzyme fatty acid amide hydrolase (FAAH) (Cravatt and Lichtman, 2002; Fegley et al, 2004, 2005). Pharmacological tools are available to block these two steps in the inactivation of endogenously released anandamide (Piomelli, 2003). AM-404 inhibits the transport of anandamide into cells where it is metabolized by FAAH (Piomelli et al, 1999) and URB-597 inhibits intracellular FAAH activity (Kathuria et al, 2003; Fegley et al, 2004, 2005). Administration of these compounds or genetic ablation of the FAAH enzyme results in increased levels of anandamide in brain tissue and peripheral blood (Giuffrida et al, 2000; Kathuria et al, 2003; Fegley et al, 2005) and in the potentiation and prolongation of anandamide's effects (Calignano et al, 1997a; Cravatt et al, 2001; Kathuria et al, 2003).

In this study, we further explored the involvement of the endogenous cannabinoid system in the reinforcing effects of opioids by measuring the effects of directly acting cannabinoid $\mathrm{CB}_{1}$ receptor agonists and indirectly acting inhibitors of endogenous cannabinoid transport into cells and intracellular FAAH metabolism on heroin self-administration under two different schedules of intravenous drug injection. These two schedules, fixed-ratio and progressiveratio schedules of drug injection, are differentially sensitive to specific pharmacological, environmental, or surgical manipulations and probably measure different aspects of drug reinforcement processes (Arnold and Roberts, 1997; Solinas et al, 2003, 2004a). Under a one-response fixed-ratio (FR1) schedule of drug self-administration, only a single response is required for each drug injection. FR1 schedules are typically used to study levels and patterns of drug intake. However, it may be difficult to determine whether changes in self-administration responding under FR1 schedules are due to increases or decreases in the reinforcing efficacy of the self-administered drug (Arnold and Roberts, 1997). This difficulty can be overcome by comparing the effects of pharmacological treatments under simple FR schedules and under more complex procedures such as progressive-ratio schedules (Arnold and Roberts, 1997). With progressive-ratio schedules, the number of responses the subject must make in order to obtain each successive drug injection progressively increases within a session until the subject stops responding. This end point, generally referred to as a 'break point', is believed to be a direct measure of the motivational strength of the reinforcing event (Hodos, 1961). Thus, progressive-ratio schedules can provide important information on the role the endogenous cannabinoid system plays in facilitating the reinforcing effects of heroin.

\section{MATERIALS AND METHODS}

\section{Subjects}

Male Sprague-Dawley rats (Charles River, Wilmington, Mass., USA) experimentally naive at the start of the study and initially weighing 300-350 g were used for all experiments. All rats were housed individually in a temperatureand humidity-controlled room and were maintained on a 12-h light/dark cycle; the lights were on from 0645 to 1845 hours. Experiments were conducted during the light phase. Rats had free access to food until recovery from surgery for implantation of i.v. catheters. One day before the start of daily self-administration sessions, food was restricted to approximately $15 \mathrm{~g} /$ day. Food was always given shortly after the end of daily experimental sessions. Water was available ad libitum for all animals. Animals used in this study were maintained in facilities fully accredited by the American Association for the Accreditation of Laboratory Animal Care (AAALAC) and all experiments were conducted in accordance with the guidelines of the Institutional Care and Use Committee of the Intramural Research Program, National Institute on Drug Abuse (NIDA), National Institutes of Health and the Guidelines for the Care and Use of Mammals in Neuroscience and Behavioral Research (National Research Council, 2003).

\section{Catheterization}

Catheters were implanted in the right jugular vein under aseptic conditions using i.p. ketamine $(60 \mathrm{mg} / \mathrm{kg})$ and xylazine $(10 \mathrm{mg} / \mathrm{kg})$ anesthesia. Catheters consisted of approximately $4 \mathrm{~cm}$ of Silastic tubing $(0.044 \mathrm{~mm}$ ID, $0.814 \mathrm{~mm}$ OD) connected to vinyl tubing (Dural Plastics, $0.5 \mathrm{~mm}$ ID, $1.0 \mathrm{~mm}$ OD) with a $23-\mathrm{g}$ stainless-steel tube and bonded with polyethylene shrink tubing. A $10-\mathrm{mm}$ long section of Tygon tubing ( $5 \mathrm{~mm}$ OD) was glued to the catheter at the midpoint of the vinyl tubing and used as a subcutaneous anchor when the catheter exited the skin in the neck. The right external jugular vein was exposed by blunt dissection and the silastic portion of the catheter was inserted into the vein and sutured into place. The vinyl portion of the catheter was passed subcutaneously to the back of the neck, where the tip exited and was obturated with a modified 23-g needle. The incision was closed with stainless-steel wound clips. A $20 \mathrm{~mm}$ plastic bolt was cemented with dental acrylic to four stainless-steel jeweler's 
screws implanted in the skull. During experimental sessions, the catheter was connected to the injection pump via tubing passing through a metal spring that was attached to the plastic bolt on the rats' head. Catheters were flushed before and after each session with $0.1 \mathrm{ml}$ of saline solution.

\section{Heroin Self-Administration Apparatus and Procedure}

Experimental chambers $(30 \times 24 \times 29 \mathrm{~cm}$, Coulbourn Instruments, Allentown, Pa., USA) were enclosed individually in sound-attenuation chests. Each experimental chamber had a metal grid floor, a recessed food tray, and two nosepoke holes in the right wall. A $4500-\mathrm{Hz}$ auditory stimulus was provided by a Sonalert (model \#628) operated at $8.75 \mathrm{~V}$. Illumination was provided by a shielded white light bulb (type \#1820) at all times except during injection and timeout periods, when both the tone and the light were pulsed at a rate of $5 \mathrm{~Hz}$, with one stimulus on while the other was off. Drug solution was delivered through Tygon tubing, protected by a metal spring and suspended through the ceiling of the experimental chamber from a single-channel fluid swivel. This tubing was attached to a syringe pump (Med Associates, St Albans, Vt., USA) that delivered fluid at a rate of $3.19 \mathrm{ml} / \mathrm{min}$ using a $10-\mathrm{ml}$ syringe. Unit doses were manipulated by computerized adjustment of the duration of the injection (0.5-2 s). Experimental events were controlled by microcomputers using Med Associates interface and software (Med Associates Inc., East Fairfield, Vt., USA).

Heroin self-administration under a FR1 schedule. Selfadministration sessions began approximately 1 week after catheter implantation. A single response in the left nosepoke hole immediately activated the injection pump and also caused the house light to flash and a tone to pulse for $5 \mathrm{~s}$. During this $5-\mathrm{s}$ time-out period, responding had no programmed consequences. Following the time-out, the next response in the left hole was reinforced. Responses in the nose-poke hole on the right side were recorded but never reinforced. Sessions lasted $3 \mathrm{~h}$. During initial training, a unit dose of $100 \mu \mathrm{g} / \mathrm{kg} /$ injection heroin was made available under the FR1 schedule described above. All rats began selfadministering heroin within a few sessions. When consistent self-administration responding was obtained, the dose of heroin was reduced to $50 \mu \mathrm{g} / \mathrm{kg} /$ injection and sessions were run until a stable baseline was reached. Baseline responding was considered stable when the number of injections per session did not differ more than $10 \%$ for three consecutive days. After stabilization rats were either tested with THC or moved to the progressive-ratio schedule.

Heroin self-administration under a progressive-ratio schedule. Rats first learned to respond for heroin under a FR1 schedule as described above and then were switched to the progressive-ratio schedule. Under the progressive-ratio schedule of i.v. drug injection, the response requirement increased with each successive injection. The steps of the exponential progression were the same as developed by Roberts and Bennett (1993) and previously used by us (Solinas et al, 2003, 2004a), based on the equation: response ratio $=\left(5 \times \mathrm{e}^{(0.2 \times \text { infusion number })}\right)-5$, rounded to the nearest integer. Thus, the values of the steps were $1,2,4,6,9,12,15$, $20,25,32,40,50,62,77,95,118,145,178,219,268,328,402$,
492, 603, and 737. Sessions under the progressive-ratio schedule lasted $5 \mathrm{~h}$ or until $30 \mathrm{~min}$ passed without a response. The breaking point was defined as the step number of the last ratio completed before $30 \mathrm{~min}$ of nonresponse or at the end of the $5 \mathrm{~h}$.

Within three to five sessions, rats reached stability under the progressive-ratio schedule. Baseline responding was considered stable when the number of injections per session did not differ more than $10 \%$ for three consecutive days. Rats were then either tested with different doses of cannabinoid compounds administered in a random order or switched to a different dose of heroin. Each compound was tested on one group only. Between test sessions, there were at least two control sessions in order to re-establish baseline responding. Different injection doses of heroin for self-administration were made available in descending order $(100,50,25,12.5 \mu \mathrm{g} / \mathrm{kg} /$ injection $)$.

\section{Drugs}

Heroin (National Institute on Drug Abuse, Baltimore, MD, USA) was dissolved in distilled water. Delta-9-THC (National Institute on Drug Abuse) $50 \mathrm{mg} / \mathrm{ml}$ in ethanol was dissolved in a solution $40 \% \mathrm{w} / \mathrm{v}$ of cyclodextrin (RBI/ SIGMA, Natick, MA, USA). WIN55,212-2 (RBI-Sigma) was suspended in $0.3 \%$ Tween-80 in saline and administered i.p. in a volume of $2 \mathrm{ml} / \mathrm{kg}$. AM-404 (synthesized at the University of Connecticut, Storrs, CT, USA) was suspended in $0.3 \%$ Tween-80 in saline and administered i.p. in a volume of $2 \mathrm{ml} / \mathrm{kg} 60 \mathrm{~min}$ before the start of the session. URB-597 was synthesized as previously described (Mor et al, 2004) and donated by Drs A Duranti, A Tontini, G Tarzia, and D Piomelli. URB-597 was dissolved in a 50\% DMSO $/ \mathrm{H}_{2} \mathrm{O}$ solution and administered i.p. in a volume of $2 \mathrm{ml} / \mathrm{kg} 40 \mathrm{~min}$ before the start of the session.

\section{Data Analysis}

Data for the effects of different doses of THC on FR1 schedules of heroin self-administration were analyzed as number of injections $( \pm S E M)$ per session. Data were subjected to a repeated measures ANOVA, followed by post hoc Dunnett's test with comparisons with the baseline condition.

Data for the effects of the $3 \mathrm{mg} / \mathrm{kg}$ dose of THC on FR1 schedules of heroin self-administration were further analyzed as number of injections $( \pm$ SEM) per 30 -min block of each session. These data were subjected to a repeated measures two-way ANOVA, followed by post hoc StudentNewman-Keuls' test. Patterns of responding during these sessions were also analyzed by sorting the postinjection pauses from each session into 1-min bins and displaying them as relative frequency distributions. These data (showing the percentage \pm SEM of postinjection pauses in each bin) were subjected to a repeated measures two-way ANOVA, with paired comparisons performed using the Student-Newman-Keuls' test.

Variability in patterns of responding under the FR1 schedule was analyzed using root mean square of successive differences (rMSSD; for details, see Tornatzky and Miczek, 2000; Panlilio et al, 2003). As the mean postinjection pauses differed between baseline responding and responding after 
injections of $3 \mathrm{mg} / \mathrm{kg}$ of THC, rMSSD was scaled by dividing it by the mean postinjection pause for each rat (see Panlilio et al, 2003). Data were subjected to a repeated measures two-way ANOVA, followed by post hoc Student-NewmanKeuls' test.

Self-administration data for the effects of THC, WIN55,212-2, AM-404 and URB-597 on progressive-ratio schedules of heroin self-administration were analyzed as last (maximal) ratio completed per session $( \pm$ SEM) after a logarithmic transformation for the progressive-ratio experiments. Data were subjected to a repeated measures ANOVA, followed when appropriate by post hoc Dunnett's test with comparisons with the base line condition. For analysis of the effects of THC $1 \mathrm{mg} / \mathrm{kg}$ on heroin self-administration over a wide range of heroin doses, data were subjected to a repeated measures two-way ANOVA, followed by post hoc Student-Newman-Keuls' test. Changes were considered significant when $P<0.05$.

\section{RESULTS}

\section{Effects of THC on Heroin Self-Administration under a FR1 Schedule}

Systemic administration of THC (0.3-3 mg/kg i.p.) did not increase the number of self-administered heroin injections under the FR1 schedule (Figure 1). In contrast, at the $3 \mathrm{mg} /$ $\mathrm{kg}$ dose, THC significantly reduced the number of selfadministered heroin injections (Figure 1$)(\mathrm{F}(3,18)=4.849$, $P<0.05)$. It is unlikely that this reduction was due to nonselective direct depressant effects of THC on behavior since THC at this dose does not decrease locomotor activity in rats (Sanudo-Pena et al, 2000). In addition, when we compared the number of heroin injections rats selfadministered during different phases of the experimental session (30-min blocks), numbers of self-administered heroin injections during the first and second 30-min intervals of the session were similar during baseline conditions and after $3 \mathrm{mg} / \mathrm{kg}$ of THC (Figure 2a), when the depressant effects of THC (as measured by depression of rates of food-maintained responding in a THC drug discrimination procedure (Solinas and Goldberg, personal observations) should be maximal. Rather, maximal decreases in the number of heroin injections self-administered (which did not reach statistical significance) were found later in the session. Self-administration behavior returned toward baseline levels during the last 30-min interval of the session when the rate-depressant effects of THC may have been diminishing. In addition, reduction of heroin selfadministration did not appear related to an antagonism of heroin's reinforcing effects, since the pattern of selfadministration responding after $3 \mathrm{mg} / \mathrm{kg}$ THC did not resemble that during extinction (a number of self-administered injections at the start of the session followed by almost complete cessation of responding and injections for the remainder of the session (see Ettenberg et al, 1982, for example). Visual inspection of event records (see Figure $2 \mathrm{~b}$ and $c$, for a representative sample) indicated that responding was very regular under baseline conditions (Figure $2 \mathrm{~b}$ ) but became irregular ('dysregulated') after administration of $3 \mathrm{mg} / \mathrm{kg}$ of THC (Figure 2c), with rats tending to selfadminister injections of heroin in short bursts separated by

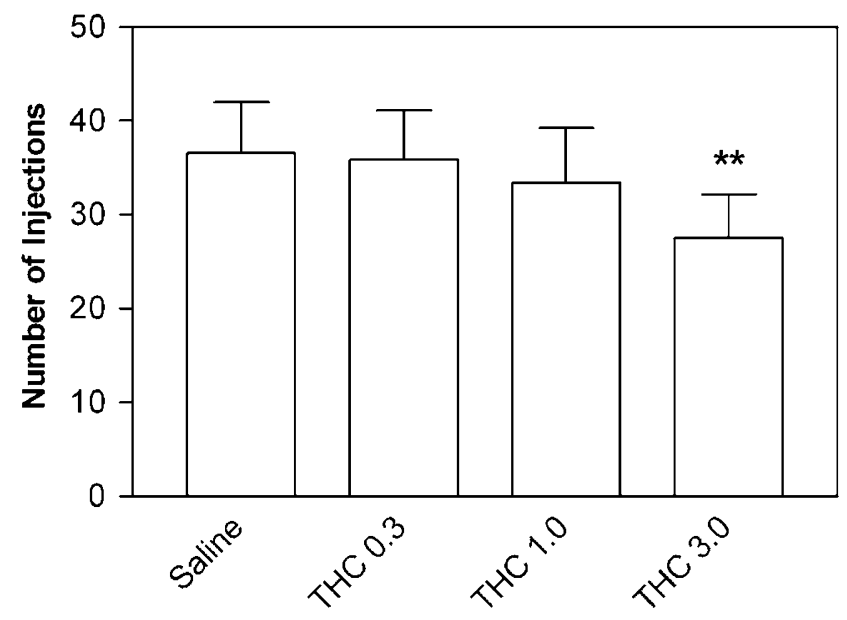

Figure I Effects of different doses of THC on self-administration of $50 \mu \mathrm{g} / \mathrm{kg}$ injections of heroin under a fixed-ratio I (FRI) schedule. Data are expressed as mean $( \pm S E M)$ number of injections per session during baseline (BL) conditions and during sessions with THC pretreatment. **, $P<0.01$. Post hoc comparison of $B L$ vs treatment session after significant ANOVA for repeated measures main effect, Dunnet's test $(n=7)$.

considerable amounts of time. Relative frequency distributions of mean postinjection pauses in responding (expressed as percentage of total injections obtained in a session) are shown in Figure 2d and confirm that THC injections produced a significant increase in the number of heroin injections that were self-administered after very short (1 min or less) or very long intervals of time $(>15 \mathrm{~min})(\mathrm{F}(1,15)=65.21, P<0.0001)$. In order to determine whether or not THC significantly changed the pattern of heroin self-administration behavior, rMSSD, a measure of the within-subject variability of sequential postinjection pauses, were determined for each rat self-administering heroin under baseline conditions (baseline sessions before and after the test session, BL1 and BL2) and after treatment with the $3 \mathrm{mg} / \mathrm{kg}$ dose of THC. The absolute levels of variability (data not shown), as well as the relative variability (Figure 2e), were significantly greater after THC administration compared to these baseline levels $(\mathrm{F}(2$, $12)=20.245, \quad P<0.0001$ and $\mathrm{F}(2,12)=18.264, P<0.001$, respectively).

In order to determine whether or not lower doses of THC altered the pattern of heroin self-administration during the session in ways that would not be reflected in whole session means for self-administered injections, the pattern of heroin self-administration during the 3 -h sessions (number of injections during each 30-min block of the session) and the distribution of mean postinjection pauses (rMSSD) were analyzed and event records were visually inspected at these doses. We found that administration of 0.3 and $1 \mathrm{mg} / \mathrm{kg}$ doses of THC did not produce any change in the patterns of heroin self-administration compared to baseline levels (data not shown), confirming our finding that only a high $3 \mathrm{mg} / \mathrm{kg}$ dose of THC alters heroin self-administration under a FR1 schedule. Thus, under a FR1 schedule of intravenous heroin self-administration, a high, but not a low or intermediate, dose of THC reduced the number of injections selfadministered per session, but this decrease could not be easily interpreted as a decrease or an increase in the reinforcing efficacy of heroin. Given the difficulties in 

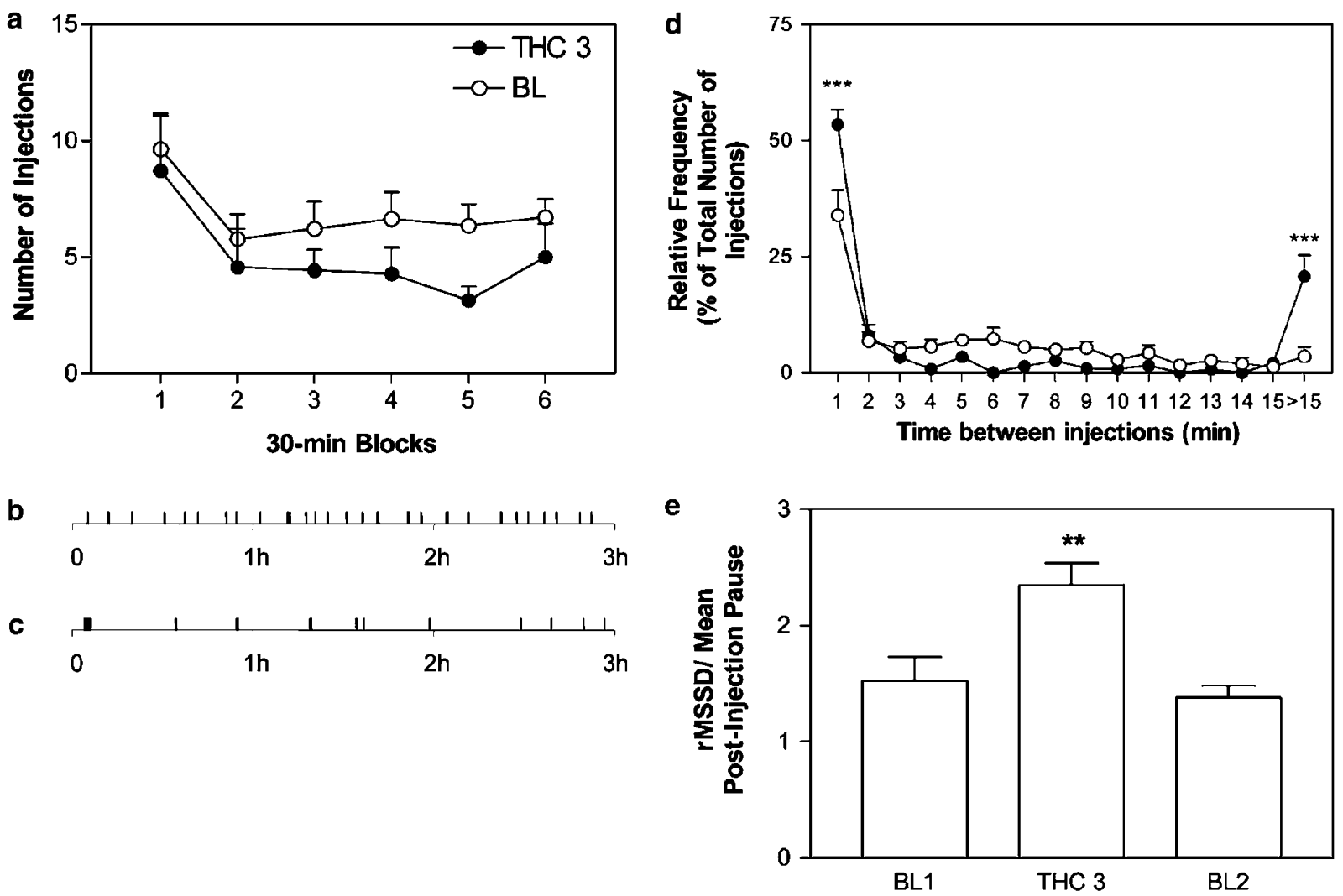

Figure 2 Effects of pretreatment with $3 \mathrm{mg} / \mathrm{kg}$ of THC on the pattern of self-administration of $50 \mu \mathrm{g} / \mathrm{kg}$ injections of heroin under a fixed-ratio I (FRI) schedule. Data in (a) are expressed as mean ( \pm SEM) number of injections in six consecutive 30-min blocks for a total $3 \mathrm{~h}$ session, during baseline conditions (empty symbols) and during the session with THC pretreatment (filled symbols). Representative event records of one rat under baseline (BL) conditions (b) and during the session with THC pretreatment (c) are shown. Data in (d) are expressed as mean ( \pm SEM) of the percentage of heroin injections that occurred after each indicated postreinforcement time expressed in minutes during baseline conditions (empty symbols) and during the session with THC pretreatment (filled symbols). Data in (e) are expressed as mean ( \pm SEM) of the within-subject rMSSD of latencies in sec between consecutive injections of heroin scaled by mean latency during baseline conditions (BLI and BL2) and during the session with THC pretreatment. Note that BLI represents the baseline condition before and BL2 the baseline condition after the test (THC 3) session. **, $P<0.05$; ***, $P<0.00$ I. Post hoc comparison with vehicle controls after significant two-way ANOVA main effect, Student-Newman-Keuls' test $(n=7)$.

interpreting the effects of THC on self-administration of heroin under FR1 schedules, we decided to investigate the effects of THC on heroin self-administration under a progressive-ratio schedule.

\section{Effects of THC on Heroin Self-Administration under a Progressive-Ratio Schedule}

Systemic administration of THC significantly and dosedependently increased the break point for self-administration of a $50 \mu \mathrm{g} / \mathrm{kg}$ injection dose of heroin under the progressive-ratio schedule, as measured by number of injections in the session and by the corresponding last ratio completed (Figure 3a) $(\mathrm{F}(5,15)=5.421, P<0.01)$. An i.p. dose of $1 \mathrm{mg} / \mathrm{mg}$ THC produced the peak effect, while a higher $3 \mathrm{mg} / \mathrm{kg}$ dose of THC increased break points in some rats but completely disrupted responding in other rats, resulting in an inverted U-shaped dose-response curve (Figure 3a).

When heroin injection dose was varied, the $1 \mathrm{mg} / \mathrm{kg}$ dose of THC significantly increased the number of injections per session and the corresponding last ratio completed (Figure 3b) over a wide range of heroin doses (Dose, $\mathrm{F}(6,18)=5.588$, $P<0.01$; Treatment, $\mathrm{F}(1,6)=16.205, P<0.01)$, resulting in upward shifts, rather than left-ward shifts, in the doseresponse curves for heroin self-administration. Thus, THC pretreatment appeared to increase the reinforcing efficacy rather than the potency of heroin.

Representative cumulative-response records are shown in Figure 4 for the effects of $1 \mathrm{mg} / \mathrm{kg}$ THC on self-administration of several injection doses of heroin. THC increased responding for self-administration of all heroin injection doses studied, with the exception of the highest $100 \mu \mathrm{g} / \mathrm{kg}$ injection dose of heroin. At this dose of heroin, any increase in heroin's reinforcing efficacy may have been masked by direct depressant effects of heroin or the combination of heroin and THC.

\section{Effects of WIN55,212-2 on Heroin Self-Administration under a Progressive-Ratio Schedule}

Systemic administration of the synthetic CB1 agonist WIN55,212-2 significantly and dose-dependently increased the break point for self-administration of a $50 \mu \mathrm{g} / \mathrm{kg}$ injection dose of heroin under the progressive-ratio schedule, as measured by number of injections in the session and by the corresponding last ratio completed (Figure 5) $\quad(\mathrm{F}(3,21)=5.473, \quad P<0.01)$. Consistent with 


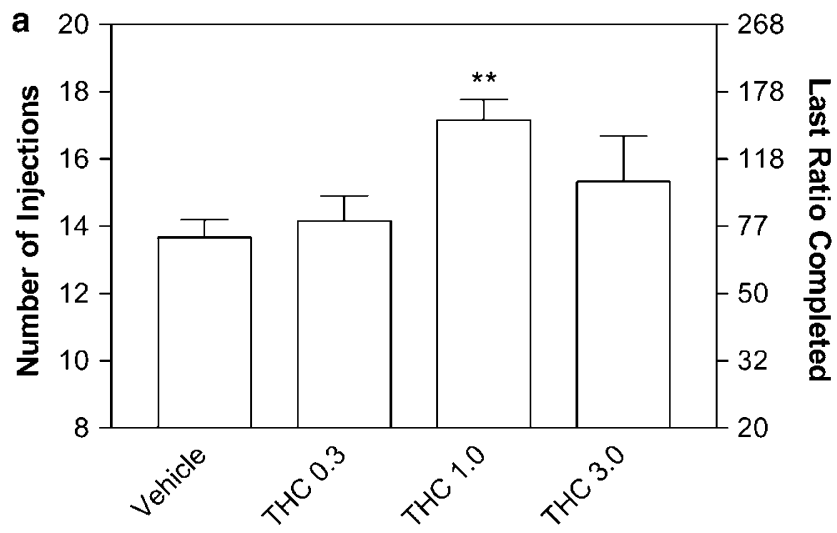

Dose of THC (mg/kg i.p.)

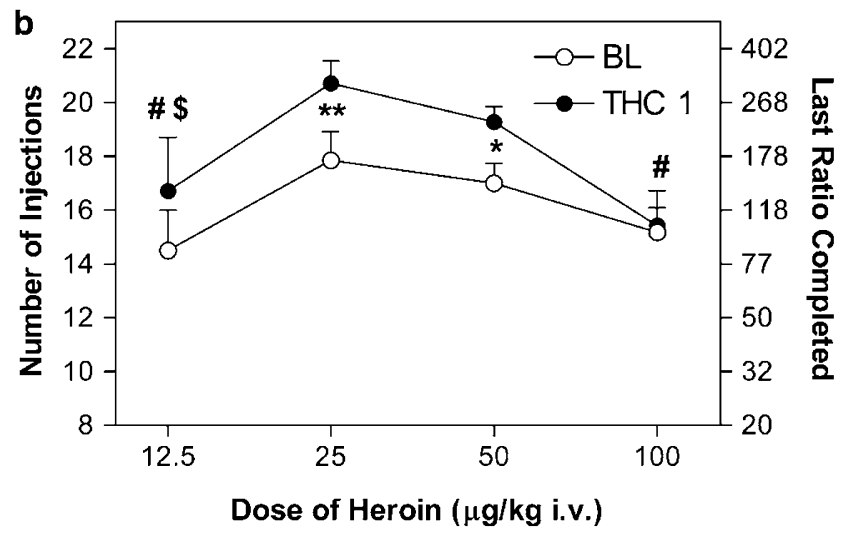

Figure 3 Effects of THC pretreatment on self-administration of heroin under a progressive-ratio schedule. Data are expressed as mean ( \pm SEM) number of injections per session (left ordinates) and the corresponding last ratios completed (right ordinates) during baseline (BL) conditions and during sessions with THC pretreatment. Panel (a) shows the effects of different doses of THC on self-administration of a fixed dose $(50 \mu \mathrm{g} / \mathrm{kg} /$ injection) of heroin. ***, $P<0.0$ I. Post hoc comparison of $B L$ vs treatment session after significant ANOVA for repeated measures main effect, Dunnet's test $(n=6)$. Panel (b) shows the effects of pretreatment with a single I mg/ $/ \mathrm{kg}$ dose of THC on self-administration of different doses (I2.5$100 \mu \mathrm{g} / \mathrm{kg} /$ injection) of heroin. *, $P<0.05 ; * *, P<0.01$ indicate differences between baseline vs treatment session. \#, $P<0.05$ indicates differences from the heroin dose of $25 \mu \mathrm{g} / \mathrm{kg} /$ injection. $\$, P<0.05$ indicates differences from the heroin dose of $50 \mu \mathrm{g} / \mathrm{kg} /$ injection. Two-way ANOVA for repeated measures main effect, Student-Newman-Keuls' test $(n=7)$.

previous studies (Wiley et al, 1995), the potency of WIN55,212-2 was similar to that of THC, with a peak effect at an i.p. dose of $1 \mathrm{mg} / \mathrm{mg}$.

\section{Effects of Compounds that Inhibit Transport into Cells or Intracellular Metabolism of Endogenous Cannabinoids on Heroin Self-Administration under a Progressive-Ratio Schedule}

Systemic administration of AM-404 or URB-597 can increase blood and brain levels of the endogenous cannabinoid anandamide (Giuffrida et al, 2000; Kathuria et al, 2003; Fegley et $a l, 2005$ ) and should increase the duration of action of any anandamide released by heroin. Systemic administration of AM-404 (1-10 mg/kg given i.p. $60 \mathrm{~min}$ before the session) or URB-597 (0.01-0.3 mg/kg given i.p. $40 \mathrm{~min}$ before the session) did not increase the break point for heroin self-administration under the progressive-ratio schedule, as measured by number of heroin injections self-administered per session or the corresponding last ratio completed (Figure 6a and b) at any dose of AM-404 or URB-597 tested. To the contrary, at the highest dose tested, AM-404 (10 mg/kg) significantly decreased the break point for heroin self-administration $(\mathrm{F}(3,27)=3.668, \quad P<0.05)$ without significantly affecting rates of nose-poke responding in the inactive hole (data not shown).

Results were similar when the $3 \mathrm{mg} / \mathrm{kg}$ dose of AM-404 (the highest dose of AM-404 that did not decrease heroin self-administration) was coadministered with different doses of URB-597 (0.01-0.3 mg/kg). There was no increase in the number of heroin injections self-administered or the corresponding last ratio completed (Figure 7). However, coadministration of $3 \mathrm{mg} / \mathrm{kg} \mathrm{AM}-404$ and 0.1 or $0.3 \mathrm{mg} / \mathrm{kg}$ URB-597, which by themselves did not alter the number of heroin injections self-administered per session or the last ratio completed, significantly decreased these values when given together (Figure 7$)(\mathrm{F}(4,28)=3.008, P<0.05)$ without significantly affecting rates of nose-poke responding in the inactive hole (data not shown).

\section{DISCUSSION}

The reinforcing efficacy of heroin measured under the progressive-ratio schedule of intravenous heroin selfadministration was significantly enhanced by THC administration. The increase in heroin's reinforcing efficacy produced by THC resulted in an upward shift in the full heroin dose-effect function. This indicates that combinations of THC and heroin produced synergistic effects that were greater than those of heroin alone. WIN55,212-2, a synthetic compound $\mathrm{CB} 1$ receptor agonist that activates $\mathrm{CB}_{1}$ receptors with a potency similar to THC in vivo (Wiley et al, 1995), also enhanced the reinforcing efficacy of heroin under the progressive-ratio schedule. The similar effects of THC and WIN55,212-2 in increasing break points for intravenous self-administration of heroin under the progressive-ratio schedule provide additional evidence that activation of cannabinoid $C_{1}$ receptors can increase the reinforcing efficacy of opioids. In previous studies, we and others further demonstrated that the reinforcing effects of heroin in rats are reduced by the cannabinoid $\mathrm{CB}_{1}$ receptor antagonist rimonabant (SR-141716A) (Navarro et al, 2001; Caille and Parsons, 2003; De Vries et al, 2003; Solinas et al, 2003). In addition, genetic ablation of cannabinoid $\mathrm{CB}_{1}$ receptors decreases the rewarding effects of opiates (Ledent et al, 1999; Mascia et al, 1999; Martin et al, 2000). The present findings that the reinforcing effects of heroin are enhanced by cannabinoid $\mathrm{CB}_{1}$ receptor agonists extend these previous findings and clearly demonstrate an important facilitatory role for the cannabinoid system in the reinforcing effects of opioids.

Although the reinforcing efficacy of heroin was significantly enhanced under the progressive-ratio schedule at an intermediate $1 \mathrm{mg} / \mathrm{kg}$ dose of THC in the present study, a higher $3 \mathrm{mg} / \mathrm{kg}$ dose of THC no longer produced significant enhancement. This finding is consistent with reported findings of biphasic effects of THC, with low doses having 

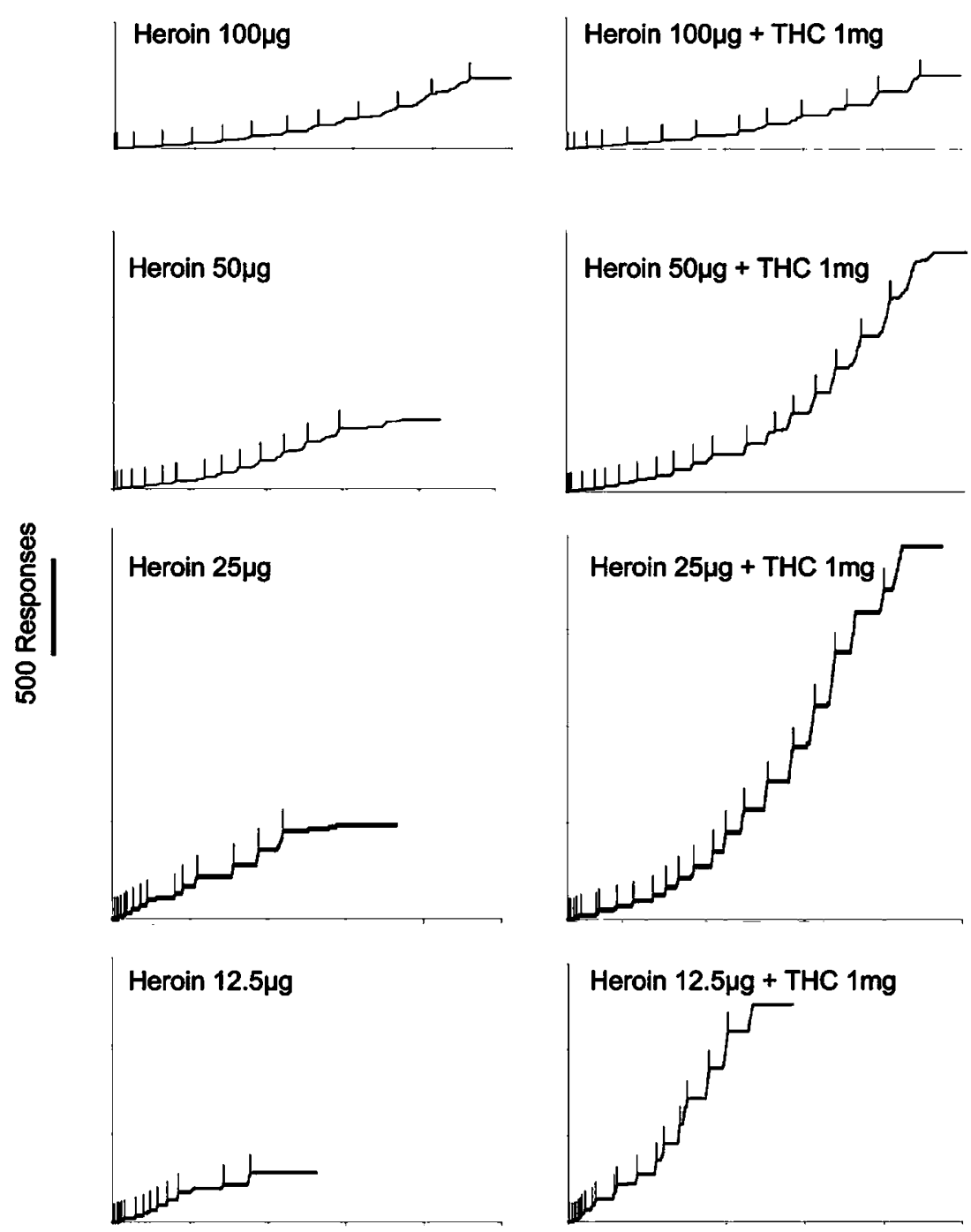

1 Hour

Figure 4 Representative cumulative-response records of heroin self-administration under the progressive-ratio schedule. Ordinates represent cumulative number of nose-poke responses and abscissas represent time. On the left-hand side of the graph, records representative of behavior at different doses of heroin under baseline conditions are shown. At doses of $12.5,25,50$, and $100 \mu \mathrm{g} / \mathrm{kg} /$ injection, the number of injections of heroin self-administered per session was 13,15, 14, and 13 and the last ratio completed was 62,95, 77, and 62, respectively. On the right-hand side of the graph, records representative of behavior at different doses of heroin after pretreatment with THC are shown. After THC pretreatment, the number of injections of heroin selfadministered per session at doses of $12.5,25,50$, and $100 \mu \mathrm{g} / \mathrm{kg} /$ injection was 19,21, 19, and 13, and the last ratio completed was $219,328,219$, and 62 , respectively. Note that an increase in break point was evident at all doses from 12.5 to $50 \mu \mathrm{g} / \mathrm{kg} / \mathrm{injection}$, but not at the highest $100 \mu \mathrm{g} / \mathrm{kg} / \mathrm{injection}$ dose.

activating and reinforcing effects and higher doses having depressant and aversive effects (Lepore et al, 1995; SanudoPena et al, 2000; Valjent and Maldonado, 2000). Thus, the lack of effect found at the $3 \mathrm{mg} / \mathrm{kg}$ dose of THC may be due to depressant effects of THC at this dose or to synergistic depressant effects of experimenter-administered THC and heroin self-administered by the rats. This second possibility is supported by our finding in another study (Solinas and Goldberg, 2005) that examined the effects of THC on responding for food pellets under a progressive-ratio schedule. In that study, a $1 \mathrm{mg} / \mathrm{kg}$ dose of THC did not alter responding for food, but $3 \mathrm{mg} / \mathrm{kg}$ THC produced peak increases in the break points for food, suggesting that combined effects of heroin and THC, rather than THC's effects alone, were responsible for the failure of $3 \mathrm{mg} / \mathrm{kg}$
THC to increase the break point for heroin self-administration in the present study. Decreases in response output due to THC-heroin combinations could also be responsible for the lack of increases in break points when $1 \mathrm{mg} / \mathrm{kg}$ of THC was administered to rats self-administrating the high $100 \mu \mathrm{g} / \mathrm{kg}$ injection dose of heroin. Thus, direct depressant effects of $100 \mu \mathrm{g} / \mathrm{kg}$ injections of heroin in combination with a potentially enhancing $1 \mathrm{mg} / \mathrm{kg}$ dose of THC may have produced synergistic depression of responding that masked an increase in reinforcing efficacy of heroin.

In contrast to results under the progressive-ratio schedule of heroin self-administration, we only observed THCinduced decreases in heroin self-administration under a FR1 schedule. It is well known that a decrease in heroin selfadministration under a FR1 schedule can result from either 


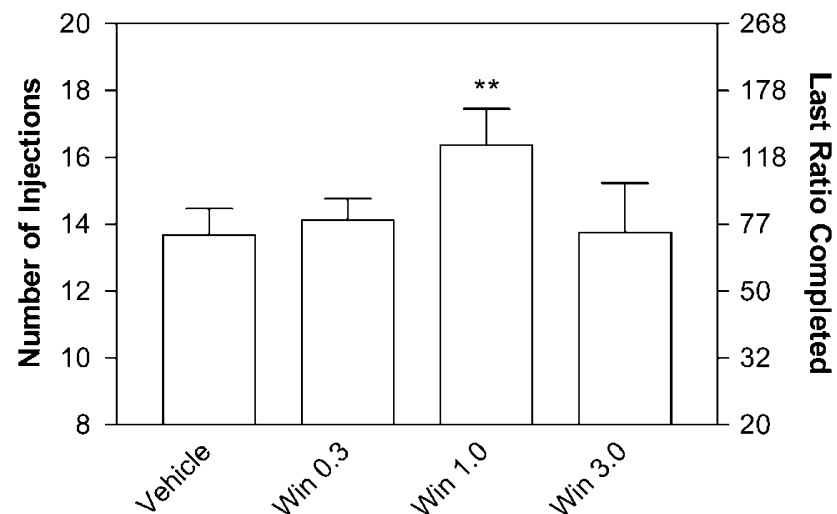

Figure 5 Effects of pretreatment with different doses of WIN55,2 I2-2 on self-administration of $50 \mu \mathrm{g} / \mathrm{kg}$ injections of heroin under a progressiveratio schedule. Data are expressed as mean $( \pm S E M)$ number of injections per session (left ordinates) and the corresponding last ratios completed (right ordinates) during baseline conditions and during sessions with WIN55,2I 2-2 pretreatment. **, $P<0.0$ I. Post hoc comparison of $B L$ vs treatment session after significant ANOVA for repeated measures main effect, Dunnet's test $(n=8)$.
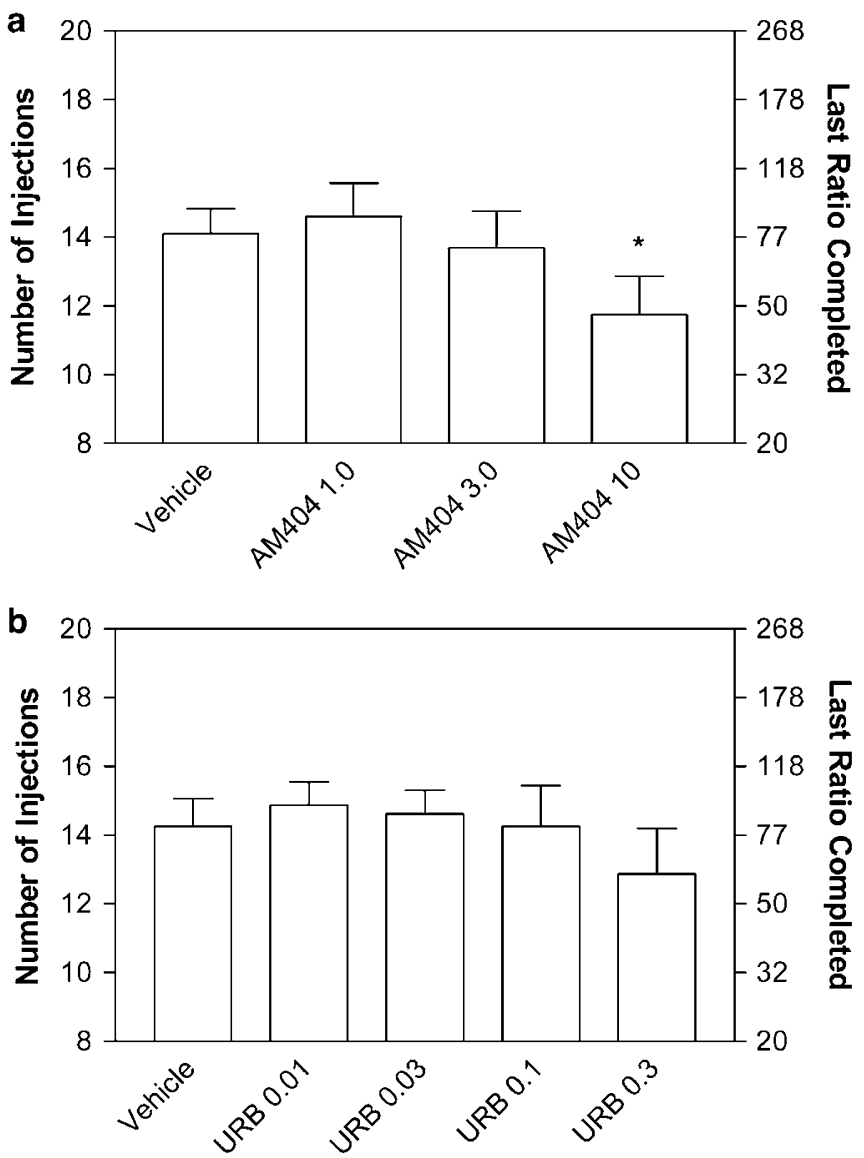

Figure 6 Effects of pretreatment with different doses of AM-404 (a) or URB-597 (b) on self-administration of $50 \mu \mathrm{g} / \mathrm{kg}$ injections of heroin under a progressive-ratio schedule. Data are expressed as mean $( \pm$ SEM) number of injections per session (left ordinates) and corresponding last ratios completed (right ordinates) during baseline (BL) conditions and during sessions with AM-404 $(n=10)$ or URB-597 $(n=8)$ pretreatment. $*, P<0.05$. Post hoc comparison of BL vs treatment session after significant ANOVA for repeated measures main effect, Dunnet's test.

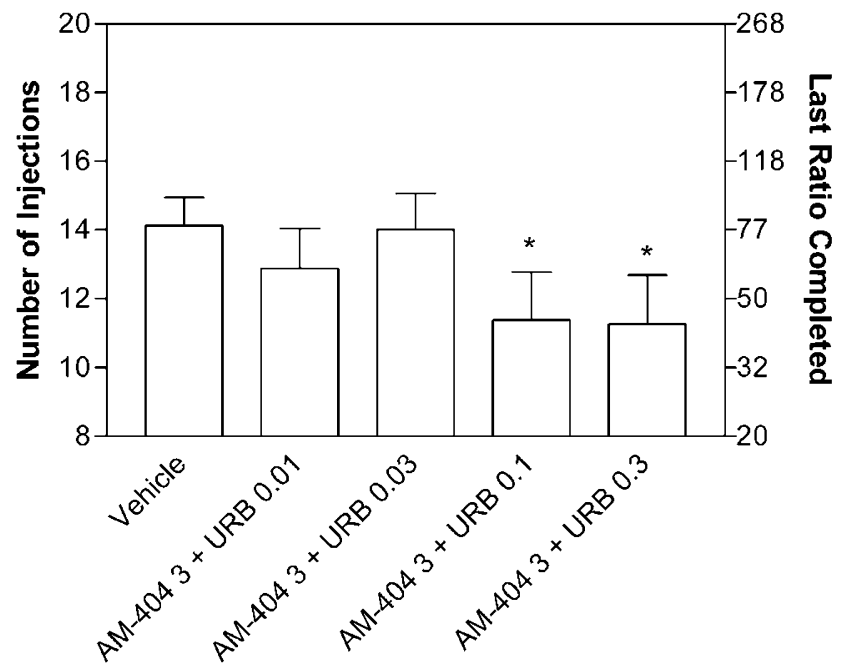

Figure 7 Effects of pretreatment with combinations of AM-404 and URB-597 on self-administration of $50 \mu \mathrm{g} / \mathrm{kg}$ injections of heroin under a progressive-ratio schedule. Data are expressed as mean ( \pm SEM) number of injections per session (left ordinates) and the corresponding last ratios completed (right ordinates) during baseline (BL) conditions and during sessions in which combinations of $3 \mathrm{mg} / \mathrm{kg}$ of AM-404 and different doses of URB-597 were administered. *, $P<0.05$. Post hoc comparison of $B L$ vs treatment session after significant ANOVA for repeated measures main effect, Dunnet's test $(n=8)$.

an increase in reinforcing efficacy (eg, when the dose of heroin is increased) or a decrease in reinforcing efficacy (eg, when the dose of heroin is decreased) (Arnold and Roberts, 1997). Thus, a FR1 schedule of drug self-administration is well suited for measuring changes in drug intake, but not for detecting changes in reinforcing efficacy. An in-depth analysis of self-administration behavior under the FR 1 schedule showed that THC-induced reductions in self-administered heroin injections were accompanied by a change in the pattern of self-administered injections within individual sessions. Under baseline conditions, heroin selfadministration was relatively regular, but after THC administration heroin self-administration became irregular ('disregulated'), that is, animals tended to self-administer heroin in bursts of several injections followed by relatively long pauses. Burst-like patterns have been observed after long sessions of cocaine self-administration (Ahmed and Koob, 1998; Tornatzky and Miczek, 2000) and the question has been raised whether such patterns were due to a 'local tolerance or sensitization', that is, a short-lasting decrease or increase, respectively, in the reinforcing efficacy of the drug (Koob et al, 1998). Although these THC-induced decreases in heroin intake under the FR1 schedule may be interpreted as consistent with our findings that THC and other directly-acting cannabinoid $\mathrm{CB}_{1}$ agonists can increase the reinforcing efficacy of heroin under the progressiveratio schedule, the burst-like patterns of self-administration behavior observed under the FR1 schedule after THC administration do not necessarily reflect 'local' changes in reinforcing efficacy of heroin. Variability in response patterns for drug self-administration is influenced by many factors other than reinforcing efficacy (Panlilio et al, 2003). For example, regulated drug intake depends heavily on pharmacokinetics and the detection of drug levels by the animal (Tsibulsky and Norman, 1999). High doses of THC 
may have altered the discriminative stimulus effects of heroin under the FR1 schedule or in some other way disrupted the rats' ability to detect the effects of the selfadministered heroin. The present results demonstrate once more the difficulties inherent in interpreting changes in response rates under FR1 schedules of drug injection as changes in reinforcing efficacy and the necessity of comparing the influences of experimental manipulations on different schedules of reinforcement and analyzing patterns of responding in addition to rates of responding.

Acute administration of opioid agonists such as morphine has been shown to increase anandamide levels in brain areas such as the nucleus accumbens, the caudate putamen, and the hippocampus (Vigano et al, 2004). If heroin selfadministration in this study released endogenous cannabinoids such as anandamide, brain levels of anandamide that normally are removed from the extracellular space and degraded very quickly would be increased by inhibiting transport into cells with AM-404 or inhibiting intracellular FAAH metabolism with URB-597 and this should lead to an increased activation of cannabinoid $\mathrm{CB}_{1}$ receptors similar to that produced by exogenous administration of either THC or WIN55,212-2. Behavioral testing in the present study was well within the range of doses of AM-404 and URB-597 which have been shown to produce substantial elevations in anandamide levels and enhance the effects of exogenously administered anandamide in earlier studies (Giuffrida et al, 2000; Kathuria et al, 2003; Fegley et al, 2004). The fact that neither AM-404 nor URB-597 nor their combination increased the reinforcing effects of heroin under the progressive-ratio schedule suggests that either (1) opioids do not release anandamide in brain areas mediating reinforcement processes; (2) increases in endogenous levels of anandamide produced by opioids are not sufficient to activate cannabinoid $\mathrm{CB}_{1}$ receptors in brain areas mediating reinforcement processes; or (3) URB-597 and AM-404 have secondary effects not mediated by cannabinoid $\mathrm{CB}_{1}$ receptors that counteract and mask the effects of any endogenous cannabinoids that are released.

Although AM-404 or combinations of AM-404 and URB597, at the highest doses administered, significantly reduced break points for heroin self-administration, it is unlikely that this decrease reflects a decrease in the reinforcing efficacy for heroin. In our opinion, two possible mechanisms can underlie this decrease: (1) an enhancement of the effects of released endogenous cannabinoid in brain areas involved in motor behavior may have produced depressant effects on behavior not specifically related to reinforcement of heroin self-administration behavior or (2) the decrease found at higher doses of these compounds may be related to nonspecific depressant effects produced by the drugs alone or by their combination with the effects of self-administered heroin. These depressant effects would have affected high rates of responding on the active nose-pokes, whereas low rates of responding on the inactive lever were not affected.

At the doses tested in this study, the behavioral effects of AM-404 in vivo appear to be primarily mediated by inhibition of anandamide transport into cells and the consequent elevation in extracellular levels of endogenous cannabinoids in the brain (Calignano et al, 1997a,b; Beltramo et al, 2000; Fernandez-Espejo et al, 2004; Chhatwal et al, 2005; Rodella et al, 2005). In contrast, in some in vitro experiments AM-404 activated vanilloid TRPV1 type receptors at concentrations similar to or lower than those necessary for inhibition of anandamide transport (De Petrocellis et al, 2000; Zygmunt et al, 2000; Ross et al, 2001). In addition, at the doses tested in this study, AM-404 and URB-597 increase brain levels of anandamide, which itself activates vanilloid TRPV1 type receptors (Zygmunt et al, 1999; Di Marzo et al, 2001). Vanilloid TRPV1 receptors are expressed in the brain and, particularly, in areas rich in dopaminergic cell bodies (Mezey et al, 2000), and it has been reported that their activation can lead to a release of glutamate in the VTA and substantia nigra and increased dopaminergic firing (Marinelli et al, 2003, 2004). Since inhibition of glutamate release in the VTA is believed to be responsible for cannabinoid $\mathrm{CB} 1$ receptor-induced increases in dopaminergic firing and elevations of dopamine in the nucleus accumbens (Szabo et al, 2002; Melis et al, 2004), activation of CB1 receptors by elevated anandamide levels and activation of TRPV1 receptors could have opposite effects. However, since both CB1 and TRPV1 activation results in increased dopaminergic firing (French et al, 1997; Marinelli et al, 2004), it is likely that the glutamatergic terminals on which cannabinoid CB1 and vanilloid TRPV1 receptors act are different, with $\mathrm{CB} 1$ responsive terminals making synapses on GABAergic terminals and TRPV1-responsive terminals making synapses directly on dopaminergic neurons. Thus, activation of cannabinoid CB1 and vanilloid TRPV1 receptors would produce similar and possibly additive effects. The possibility that the decreases in break point for heroin selfadministration produced by AM-404 alone or combinations of AM-404 and URB-597 were due, in whole or in part, to activation of vanilloid TRPV1 receptors deserves future investigation. Nonetheless, the fact that URB-597 did not potentiate the reinforcing effects of heroin at doses that increase anandamide levels in the brain indicates that elevations in anandamide levels do not play a role in the modulation of the reinforcing effects of heroin.

Taken together, the present findings that the reinforcing effects of heroin can be enhanced by 'direct' agonists at cannabinoid $\mathrm{CB}_{1}$ receptors but not by compounds that increase levels of endogenous cannabinoid $\mathrm{CB}_{1}$ receptor agonists, along with previous findings that $\mathrm{CB}_{1}$ receptor blockade or genetic deletion of $\mathrm{CB}_{1}$ receptors reduces the reinforcing effects of opioids (Ledent et al, 1999; Mascia et al, 1999; Martin et al, 2000; Cossu et al, 2001; Navarro et al, 2001; Caille and Parsons, 2003; De Vries et al, 2003; Solinas et al, 2003), indicate that the modulation of the reinforcing effects of heroin produced by cannabinoid $\mathrm{CB}_{1}$ receptor activation or blockade or by genetic deletion of $\mathrm{CB}_{1}$ receptors is due to interactions between opioid and cannabinoid receptors and their signaling pathways and not to an opioid-induced release of endogenous cannabinoids. Thus, in the absence of cannabinoid $\mathrm{CB}_{1}$ receptors or in conditions of pharmacological blockade of $\mathrm{CB}_{1}$ receptors, the signaling strength of mu-opioid receptors would be decreased and, conversely, with cannabinoid $\mathrm{CB}_{1}$ receptor stimulation the signaling strength of mu-opioid receptors would be increased. In a parallel manner, it has been recently demonstrated that the signaling strength of cannabinoid $C_{1}$ receptors, as measured by increased $\left({ }^{35} \mathrm{~S}\right)-\mathrm{GTP} \gamma \mathrm{S}$ binding, is significantly reduced in mice 
lacking both mu- and delta-opioid receptors (Berrendero et al, 2003). The facts that cannabinoid $\mathrm{CB}_{1}$ receptors and mu-opioid receptors have similar anatomical distributions in the brain (Matsuda et al, 1990; Herkenham et al, 1991; Rodriguez et al, 2001), that both cannabinoid $\mathrm{CB}_{1}$ receptors and mu-opioid receptors are members of the G-proteincoupled family of receptors, and that they both modulate similar transduction systems (Reisine et al, 1996; Howlett, 2002) support the hypothesis that the reduction in the reinforcing effects of opioids produced by cannabinioid $\mathrm{CB}_{1}$ receptor activation and the enhancement of the reinforcing effects of opioids produced by cannabinioid $\mathrm{CB}_{1}$ receptor blockade or deletion are due to interactions between opioid and cannabinoid receptors and their signaling pathways and not to an opioid-induced release of endogenous cannabinoids.

In a previous study, we found that a history of THC exposure did not increase the likelihood that rats would subsequently acquire heroin self-administration under a FR1 schedule and did not alter the number of injections per session or break point values under a progressive-ratio schedule (Solinas et al, 2004a). In that study, all THC exposure occurred several days prior to any heroin exposure. In contrast, in the present study, all rats acquired heroin self-administration prior to being tested with THC or WIN55,212-2 and the effects of these cannabinoid $\mathrm{CB}_{1}$ agonists were assessed while the rats were self-administering heroin. These two studies, together, suggest that previous exposure to THC does not alter the reinforcing efficacy of heroin, but simultaneous exposure to THC and heroin may enhance the reinforcing efficacy of heroin. However, neither study assessed the possibility that simultaneous exposure to THC and heroin may alter the likelihood of acquiring heroin self-administration or increase the likelihood of dependence developing in 'casual' heroin users. We are not aware of epidemiological or laboratory-based attempts to determine whether humans who experiment with the simultaneous use of cannabis and opioids report a more intense 'high' after such combinations or whether such an increase would affect the abuse potential of either drug. In most reported cases, the use of cannabis in opiate abusers takes place when they withdraw from opioids and is thought to represent an attempt to reduce withdrawal symptoms and craving for opiates (Taj et al, 1995). Nonetheless, the present results do suggest a mechanism by which marijuana consumption could potentially contribute to opioid dependence in poly-drug abusers.

In conclusion, opioid reinforcement was enhanced in this study by directly acting cannabinoid $\mathrm{CB}_{1}$ receptor agonists, but not by compounds that indirectly increase the activity of endogenous cannabinoids by blocking their uptake or metabolism. These results clearly demonstrate that cannabinoid treatments can facilitate opioid reinforcement, but they do not provide support for the hypothesis that opioid reward is directly mediated by an opioid-induced release of endogenous cannabinoids. This would be in contrast with the reinforcing effects of cannabinoid drugs such as THC, whose psychotropic effects appear to be more directly mediated by a release of endogenous opioids in brain areas involved in reward processes, such as the VTA and nucleus accumbens (Solinas et al, 2004b). Finally, the findings that URB-597 and AM-404 did not enhance, and instead reduced, the reinforcing efficacy of heroin indicates that these compounds would not pose a risk of increasing heroin drug-taking and drug-seeking in humans if they were used, as recently proposed (Piomelli, 2004), in the treatment of marijuana dependence and other aspects of drug abuse.

\section{ACKNOWLEDGEMENTS}

This work was supported by the Intramural Research Program of the National Institute on Drug Abuse, National Institutes of Health, Department of Health and Human Services and by grants from the Extramural Research Program of National Institute on Drug Abuse (DA09158 and DA03801) to Dr A Makriyannis. We thank Dr D Piomelli for advice and help with providing URB-597.

\section{REFERENCES}

Ahmed SH, Koob GF (1998). Transition from moderate to excessive drug intake: change in hedonic set point. Science 282: 298-300.

Arnold JM, Roberts DC (1997). A critique of fixed and progressive ratio schedules used to examine the neural substrates of drug reinforcement. Pharmacol Biochem Behav 57: 441-447.

Beltramo M, de Fonseca FR, Navarro M, Calignano A, Gorriti MA, Grammatikopoulos G et al (2000). Reversal of dopamine D(2) receptor responses by an anandamide transport inhibitor. J Neurosci 20: 3401-3407.

Beltramo M, Stella N, Calignano A, Lin SY, Makriyannis A, Piomelli D (1997). Functional role of high-affinity anandamide transport, as revealed by selective inhibition. Science 277: 1094-1097.

Berrendero F, Mendizabal V, Murtra P, Kieffer BL, Maldonado R (2003). Cannabinoid receptor and WIN 55 212-2-stimulated [35S]-GTPgammaS binding in the brain of mu-, delta- and kappa-opioid receptor knockout mice. Eur J Neurosci 18: 2197-2202.

Caille S, Parsons LH (2003). SR141716A reduces the reinforcing properties of heroin but not heroin-induced increases in nucleus accumbens dopamine in rats. Eur J Neurosci 18: 3145-3149.

Calignano A, La Rana G, Beltramo M, Makriyannis A, Piomelli D (1997a). Potentiation of anandamide hypotension by the transport inhibitor, AM404. Eur J Pharmacol 337: R1-R2.

Calignano A, La Rana G, Makriyannis A, Lin SY, Beltramo M, Piomelli D (1997b). Inhibition of intestinal motility by anandamide, an endogenous cannabinoid. Eur J Pharmacol 340: R7-R8.

Chhatwal JP, Davis M, Maguschak KA, Ressler KJ (2005). Enhancing cannabinoid neurotransmission augments the extinction of conditioned fear. Neuropsychopharmacology 30: 516-524.

Cossu G, Ledent C, Fattore L, Imperato A, Bohme GA, Parmentier $\mathrm{M}$ et al (2001). Cannabinoid CB1 receptor knockout mice fail to self-administer morphine but not other drugs of abuse. Behav Brain Res 118: 61-65.

Cravatt BF, Demarest K, Patricelli MP, Bracey MH, Giang DK, Martin BR et al (2001). Supersensitivity to anandamide and enhanced endogenous cannabinoid signaling in mice lacking fatty acid amide hydrolase. Proc Natl Acad Sci USA 98: 9371-9376.

Cravatt BF, Lichtman AH (2002). The enzymatic inactivation of the fatty acid amide class of signaling lipids. Chem Phys Lipids 121: $135-148$.

De Petrocellis L, Bisogno T, Davis JB, Pertwee RG, Di Marzo V (2000). Overlap between the ligand recognition properties of the 
anandamide transporter and the VR1 vanilloid receptor: inhibitors of anandamide uptake with negligible capsaicin-like activity. FEBS Lett 483: 52-56.

De Vries TJ, Homberg JR, Binnekade R, Raaso H, Schoffelmeer AN (2003). Cannabinoid modulation of the reinforcing and motivational properties of heroin and heroin-associated cues in rats. Psychopharmacology (Berl) 168: 164-169.

Di Marzo V, Bifulco M, De Petrocellis L (2004). The endocannabinoid system and its therapeutic exploitation. Nat Rev Drug Discov 3: 771-784.

Di Marzo V, Bisogno T, De Petrocellis L (2001). Anandamide: some like it hot. Trends Pharmacol Sci 22: 346-349.

Di Marzo V, Fontana A, Cadas H, Schinelli S, Cimino G, Schwartz JC, Piomelli D (1994). Formation and inactivation of endogenous cannabinoid anandamide in central neurons. Nature 372: 686-691.

Ettenberg A, Pettit HO, Bloom FE, Koob GF (1982). Heroin and cocaine intravenous self-administration in rats: mediation by separate neural systems. Psychopharmacology (Berl) 78: 204-209.

Fegley D, Gaetani S, Duranti A, Tontini A, Mor M, Tarzia G et al (2005). Characterization of the fatty-acid amide hydrolase inhibitor URB597: effects on anandamide and oleoylethanolamide deactivation. J Pharmacol Exp Ther 313: 352-358.

Fegley D, Kathuria S, Mercier R, Li C, Goutopoulos A, Makriyannis A et al (2004). Anandamide transport is independent of fattyacid amide hydrolase activity and is blocked by the hydrolysisresistant inhibitor AM1172. Proc Natl Acad Sci USA 101: 87568761.

Fernandez-Espejo E, Caraballo I, Rodriguez de Fonseca F, Ferrer B, Banoua FE, Flores JA et al (2004). Experimental parkinsonism alters anandamide precursor synthesis, and functional deficits are improved by AM404: a modulator of endocannabinoid function. Neuropsychopharmacology 29: 1134-1142.

French ED, Dillon K, Wu X (1997). Cannabinoids excite dopamine neurons in the ventral tegmentum and substantia nigra. NeuroReport 8: 649-652.

Freund TF, Katona I, Piomelli D (2003). Role of endogenous cannabinoids in synaptic signaling. Physiol Rev 83: 1017-1066.

Giuffrida A, Rodriguez de Fonseca F, Nava F, Loubet-Lescoulie P, Piomelli D (2000). Elevated circulating levels of anandamide after administration of the transport inhibitor, AM404. Eur J Pharmacol 408: 161-168.

Herkenham M, Lynn AB, Johnson MR, Melvin LS, de Costa BR, Rice KC (1991). Characterization and localization of cannabinoid receptors in rat brain: a quantitative in vitro autoradiographic study. J Neurosci 11: 563-583.

Hodos W (1961). Progressive ratio as a measure of reward strength. Science 134: 943-944.

Howlett AC (2002). The cannabinoid receptors. Prostaglandins Other Lipid Mediat 68-69: 619-631.

Justinova Z, Tanda G, Munzar P, Goldberg SR (2004). The opioid antagonist naltrexone reduces the reinforcing effects of Delta 9 tetrahydrocannabinol (THC) in squirrel monkeys. Psychopharmacology (Berl) 173: 186-194.

Kathuria S, Gaetani S, Fegley D, Valino F, Duranti A, Tontini A et al (2003). Modulation of anxiety through blockade of anandamide hydrolysis. Nat Med 9: 76-81.

Koob GF, Rocio M, Carrera A, Gold LH, Heyser CJ, MaldonadoIrizarry C et al (1998). Substance dependence as a compulsive behavior. J Psychopharmacol 12: 39-48.

Ledent C, Valverde O, Cossu G, Petitet F, Aubert JF, Beslot F et al (1999). Unresponsiveness to cannabinoids and reduced addictive effects of opiates in CB1 receptor knockout mice. Science 283: 401-404.

Lepore M, Vorel SR, Lowinson J, Gardner EL (1995). Conditioned place preference induced by delta 9-tetrahydrocannabinol: comparison with cocaine, morphine, and food reward. Life Sci 56: $2073-2080$.
Marinelli S, Di Marzo V, Berretta N, Matias I, Maccarrone M, Bernardi G et al (2003). Presynaptic facilitation of glutamatergic synapses to dopaminergic neurons of the rat substantia nigra by endogenous stimulation of vanilloid receptors. J Neurosci 23: 3136-3144.

Marinelli S, Pascucci T, Bernardi G, Puglisi-Allegra S, Mercuri NB (2004). Activation of TRPV1 in the VTA excites dopaminergic neurons and increases chemical- and noxious-induced dopamine release in the nucleus accumbens. Neuropsychopharmacology PMID 15562294.

Martin M, Ledent C, Parmentier M, Maldonado R, Valverde O (2000). Cocaine, but not morphine, induces conditioned place preference and sensitization to locomotor responses in CB1 knockout mice. Eur J Neurosci 12: 4038-4046.

Mascia MS, Obinu MC, Ledent C, Parmentier M, Bohme GA, Imperato A et al (1999). Lack of morphine-induced dopamine release in the nucleus accumbens of cannabinoid $\mathrm{CB}(1)$ receptor knockout mice. Eur J Pharmacol 383: R1-R2.

Matsuda LA, Lolait SJ, Brownstein MJ, Young AC, Bonner TI (1990). Structure of a cannabinoid receptor and functional expression of the cloned cDNA. Nature 346: 561-564.

Melis M, Pistis M, Perra S, Muntoni AL, Pillolla G, Gessa GL (2004). Endocannabinoids mediate presynaptic inhibition of glutamatergic transmission in rat ventral tegmental area dopamine neurons through activation of $\mathrm{CB} 1$ receptors. $J$ Neurosci 24: 53-62.

Mezey E, Toth ZE, Cortright DN, Arzubi MK, Krause JE, Elde R et al (2000). Distribution of mRNA for vanilloid receptor subtype 1 (VR1), and VR1-like immunoreactivity, in the central nervous system of the rat and human. Proc Natl Acad Sci USA 97: 3655-3660.

Mor M, Rivara S, Lodola A, Plazzi PV, Tarzia G, Duranti A et al (2004). Cyclohexylcarbamic acid $3^{\prime}$ - or $4^{\prime}$-substituted biphenyl3-yl esters as fatty acid amide hydrolase inhibitors: synthesis, quantitative structure-activity relationships, and molecular modeling studies. J Med Chem 47: 4998-5008.

National Research Council (2003). Guidelines for the Care and Use of Mammals in Neuroscience and Behavioral Research. The National Academy Press: Washington, DC, USA.

Navarro M, Carrera MR, Fratta W, Valverde O, Cossu G, Fattore L et al (2001). Functional interaction between opioid and cannabinoid receptors in drug self-administration. J Neurosci 21: $5344-5350$.

Ortega-Gutierrez S, Hawkins EG, Viso A, Lopez-Rodriguez ML, Cravatt BF (2004). Comparison of anandamide transport in FAAH wild-type and knockout neurons: evidence for contributions by both FAAH and the $\mathrm{CB} 1$ receptor to anandamide uptake. Biochemistry 43: 8184-8190.

Panlilio LV, Katz JL, Pickens RW, Schindler CW (2003). Variability of drug self-administration in rats. Psychopharmacology (Berl) 167: 9-19.

Piomelli D (2003). The molecular logic of endocannabinoid signalling. Nat Rev Neurosci 4: 873-884.

Piomelli D (2004). The endogenous cannabinoid system and the treatment of marijuana dependence. Neuropharmacology 47(Suppl 1): 359-367.

Piomelli D, Beltramo M, Glasnapp S, Lin SY, Goutopoulos A, Xie XQ et al (1999). Structural determinants for recognition and translocation by the anandamide transporter. Proc Natl Acad Sci USA 96: 5802-5807.

Reisine T, Law SF, Blake A, Tallent M (1996). Molecular mechanisms of opiate receptor coupling to $G$ proteins and effector systems. Ann N Y Acad Sci 780: 168-175.

Roberts DC, Bennett SA (1993). Heroin self-administration in rats under a progressive ratio schedule of reinforcement. Psychopharmacology (Berl) 111: 215-218.

Rodella LF, Borsani E, Rezzani R, Ricci F, Buffoli B, Bianchi R (2005). AM404, an inhibitor of anandamide reuptake decreases 
Fos-immunoreactivity in the spinal cord of neuropathic rats after non-noxious stimulation. Eur J Pharmacol 508: 139-146.

Rodriguez JJ, Mackie K, Pickel VM (2001). Ultrastructural localization of the CB1 cannabinoid receptor in mu-opioid receptor patches of the rat Caudate putamen nucleus. J Neurosci 21: 823-833.

Ross RA, Gibson TM, Brockie HC, Leslie M, Pashmi G, Craib SJ et al (2001). Structure-activity relationship for the endogenous cannabinoid, anandamide, and certain of its analogues at vanilloid receptors in transfected cells and vas deferens. $\mathrm{Br} J$ Pharmacol 132: 631-640.

Sanudo-Pena MC, Romero J, Seale GE, Fernandez-Ruiz JJ, Walker JM (2000). Activational role of cannabinoids on movement. Eur J Pharmacol 391: 269-274.

Solinas M, Goldberg SR (2004). Involvement of mu-, delta- and kappa-opioid receptor subtypes in the discriminative-stimulus effects of delta-9-tetrahydrocannabinol (THC) in rats. Psychopharmacology (Berl) PMID 15619107.

Solinas M, Goldberg SR (2005). Motivational effects of cannabinoids and opioids on food reinforcement depend on simultaneous activation of cannabinoid and opioid systems. Neuropsychopharmacology PMID 15812567.

Solinas M, Panlilio LV, Antoniou K, Pappas LA, Goldberg SR (2003). The cannabinoid CB1 antagonist $N$-piperidinyl-5-(4chlorophenyl)-1-(2,4-dichlorophenyl)-4-methylpyrazole-3-carboxamide (SR-141716A) differentially alters the reinforcing effects of heroin under continuous reinforcement, fixed ratio, and progressive ratio schedules of drug self-administration in rats. $J$ Pharmacol Exp Ther 306: 93-102.

Solinas M, Panlilio LV, Goldberg SR (2004a). Exposure to delta-9tetrahydrocannabinol (THC) increases subsequent heroin taking but not heroin's reinforcing efficacy: a self-administration study in rats. Neuropsychopharmacology 29: 1301-1311.

Solinas M, Zangen A, Thiriet N, Goldberg SR (2004b). Betaendorphin elevations in the ventral tegmental area regulate the discriminative effects of Delta-9-tetrahydrocannabinol. Eur $J$ Neurosci 19: 3183-3192.

Szabo B, Siemes S, Wallmichrath I (2002). Inhibition of GABAergic neurotransmission in the ventral tegmental area by cannabinoids. Eur J Neurosci 15: 2057-2061.

Taj R, Keenan E, O'Connor JJ (1995). A review of patients on methadone maintenance. Ir Med J 88: 218-219.

Tanda G, Goldberg SR (2003). Cannabinoids: reward, dependence, and underlying neurochemical mechanisms - a review of recent preclinical data. Psychopharmacology (Berl) 169: 115-134.

Tornatzky W, Miczek KA (2000). Cocaine self-administration 'binges': transition from behavioral and autonomic regulation toward homeostatic dysregulation in rats. Psychopharmacology (Berl) 148: 289-298.

Tsibulsky VL, Norman AB (1999). Satiety threshold: a quantitative model of maintained cocaine self-administration. Brain Res 839: 85-93.

Valjent E, Maldonado R (2000). A behavioural model to reveal place preference to delta 9-tetrahydrocannabinol in mice. Psychopharmacology (Berl) 147: 436-438.

Vigano D, Valenti M, Grazia Cascio M, Di Marzo V, Parolaro D, Rubino T (2004). Changes in endocannabinoid levels in a rat model of behavioural sensitization to morphine. Eur J Neurosci 20: 1849-1857.

Wiley JL, Barrett RL, Lowe J, Balster RL, Martin BR (1995). Discriminative stimulus effects of CP 55,940 and structurally dissimilar cannabinoids in rats. Neuropharmacology 34: 669-676.

Zygmunt PM, Chuang H, Movahed P, Julius D, Hogestatt ED (2000). The anandamide transport inhibitor AM404 activates vanilloid receptors. Eur J Pharmacol 396: 39-42.

Zygmunt PM, Petersson J, Andersson DA, Chuang H, Sorgard M, Di Marzo V et al (1999). Vanilloid receptors on sensory nerves mediate the vasodilator action of anandamide. Nature 400: 452-457. 